\title{
ENTRE REPUBLICANISMO Y LIBERALISMO: UNA APROXIMACIÓN AL PROBLEMA DE LA LEGITIMIDAD DESDE LA TEORÍA DE LA DEMOCRACIA DELIBERATIVA
}

\section{BETWEEN REPUBLICANISM AND LIBERALISM: AN APPROACH TO THE PROBLEM OF LEGITIMACY FROM THE THEORY OF DELIBERATIVE DEMOCRACY}

\section{${ }^{1}$ Alfonso Renato Vargas Murillo}

\section{RESUMEN}

El presente trabajo aborda algunos tópicos de la discusión contemporánea en teoría y filosofía política sobre la legitimidad democrática de los actos, instituciones y prácticas políticas, así también la propuesta de la democracia deliberativa como un ideal regulativo orientado a resolver las tensiones producidas entre las concepciones clásicas de democracia (liberal y republicana), buscando articular dialógicamente los intereses de las mayorías y minorías; donde la legitimidad de las decisiones públicas se da en base al resultado de una etapa necesaria de deliberación entre todos los actores potencialmente afectados por la decisión, en condiciones de igualdad.

Palabras Clave: Democracia deliberativa, liberalismo, republicanismo.

\section{ABSTRACT}

The present work approaches some topics of the contemporary discussion in theory and political philosophy on the democratic legitimacy of the acts, institutions and political practices, as well as the proposal of the deliberative democracy like a regulative ideal oriented to solve the tensions produced between the classic conceptions of democracy (liberal and republican), seeking to articulate dialogically the interests of the majorities and minorities, where the legitimacy of public decisions is based on the result of a necessary stage of deliberation among all the actors potentially affected by the decision, under conditions of equality.

Keywords: Deliberative democracy, liberalism, republicanism.

\footnotetext{
Bachiller en Derecho por la Universidad Privada de Tacna. Tacna-Perú. Actualmente cursa la maestría en Gobernanza Global y Derechos Humanos por la Universidad Castilla - La Mancha-España. E-mail: avargasm95@gmail.com
} 


\section{INTRODUCCIÓN}

Probablemente la democracia sea uno de los tópicos que más discusión generó en el pasado siglo y que ha sido retomada en la actualidad, tanto dentro como fuera de la academia; lo cual ha motivado una revisión de los fundamentos de los modelos de democracia adoptados por la mayoría de países occidentales. De esta manera, frente a la respuesta insuficiente de las teorías tradicionales (asociadas al modelo liberal y republicano de democracia) ante la "crisis de legitimidad" en los diversos países donde se cuestiona las instituciones y su grado de representatividad, así como el limitado campo de participación de la ciudadanía en asuntos públicos, surgen propuestas alternas que, si bien no son un rechazo a los fundamentos de la democracia occidental, plantean una serie de mecanismos que permitirían afrontar los desafíos que impone la composición compleja de la sociedad actual, buscando articular dialógicamente los intereses de las mayorías y minorías.

Esto resulta especialmente problemático en sociedades como la nuestra, caracterizadas por la pluralidad; tomando en cuenta que al hacer referencia a "lo plural" se piensa en la adhesión de los ciudadanos a posiciones diversas y hasta contradictorias respecto de sus concepciones del "mundo político y personal", generando la imperiosa necesidad de diseñar instituciones que "estén dispuestas a convivir con desacuerdos profundos, persistentes, e inerradicables, no solo acerca de lo bueno, sino de lo correcto" (Olivares, 2017, p. 173).

En este sentido, el presente trabajo tiene por objetivo describir el origen, los fundamentos y las principales características de la democracia deliberativa, así como identificar su propuesta frente al problema de la legitimidad de los actores, instituciones y prácticas políticas.

\section{LADEMOCRACIA DELIBERATIVA}

La democracia deliberativa, en cuanto concepto perteneciente a la ciencia política - como señala John Parkinson (2006)—, ha sido objeto de una larga discusión, desde diversas tradiciones teóricas. Asimismo, se ha empleado este título como etiqueta para identificar "desde el activismo radical y la protesta, a los foros consultivos comprometidos con el Estado, a las asambleas representativas, a las deliberaciones de pequeños grupos de jueces, incluso a hacer que los demás estén 'presentes' en el proceso de las deliberaciones internas de un individuo" (pp. 2-3).

Como señala Adela Cortina (2007), a fines del siglo XX se produce el "giro deliberativo de la democracia", afirma además que el primero en utilizarla (en la forma en que entendemos actualmente la democracia deliberativa) fue Josep M. Bessette en su obra Deliberative Democracy: The Majority Pinciple in Republican Government, en donde criticó las interpretaciones elitistas de la Constitución, lo cual permitió el surgimiento de este concepto desde fines de los ochenta asociado a nombres como Bernard Manin (1987) y Joshua Cohen (1989), y a principios de los noventa con Habermas (1992) y Rawls (1993); quienes empezarían a trabajar sobre el desarrollo de esta nueva corriente (p. 143). Sin embargo, los antecedentes más antiguos de este modelo se encuentran en Atenas clásica, en la idea de comunidad política recogida por Aristóteles, tal como también señala Adela Cortina:

Los ciudadanos atenienses deliberan en la asamblea antes de tomar decisiones, ponderan públicamente las ventajas e inconvenientes de las alternativas posibles en las distintas cuestiones, como expresará más tarde el verbo "deliberar", del latino "libra", es decir, balanza. Y este procedimiento que nace para tomar decisiones en política, en textos de autores como Platón o Aristóteles, pasará a aplicarse también a los individuos concretos, de forma que el prudente es aquel que sabe deliberar en el conjunto de su vida y elegir lo que le conviene. (Cortina, 2007, 144)

Siguiendo a James Fishkin (2009) para esbozar un concepto de democracia deliberativa podemos identificar, como punto de partida, una de las preocupaciones centrales de este modelo de democracia: la incorporación de la ciudadanía, "bajo condiciones en las que están efectivamente motivados para realmente pensar 
en los problemas. Este es el problema de cómo cumplir con dos valores fundamentales, igualdad política y deliberación" (p. 1). Esto traería una serie de implicancias en el diseño de las instituciones estatales y los procesos de toma de decisiones políticas, así mismo en la relación entre los ciudadanos y el Estado.

De esta manera, la ciudadanía, la opinión pública, el espacio público y la participación son elementos capitales para la construcción de una concepción deliberativa de la democracia. Sin embargo, no son elementos ajenos a otras tradiciones políticas o concepciones de la democracia, como el modelo liberal o el republicano. De allí que para poder determinar qué es la democracia deliberativa (y qué no lo es), sea necesario describir ambos modelos como procesos de evolución de la concepción de ciudadano y su participación en la vida pública.

Arthur Benz, al rastrear los orígenes del concepto de ciudadano, encuentra rastros en la Ciudad-Estado griega y en la República Romana, donde designaba al miembro libre en una comunidad política. En la Edad Media, se usaba para hacer referencia a aquellos habitantes que no estaban sometidos a vasallaje feudal. Posteriormente, durante el Renacimiento surge la distinción entre burgeois (burgués) y citoyén (ciudadano): modelos que serían unificados durante la Ilustración, donde se optó por un paradigma normativo de ciudadano (basado en la igualdad de todos aquellos que sean considerados ciudadanos); el primero designaba a quien se encontraba fuera del Estado en cuanto persona particular, y exigía derechos de libertad y garantías con la injerencia del Estado, persiguiendo sus intereses individuales, lo que podemos identificar con el modelo de "homo economicus"; el segundo, en cuanto miembro de una asociación política, era participante en la formación de la voluntad política y toma de decisiones, formando parte de la esfera pública, identificándose con el modelo de "homo politicus" (Domínguez, 2013, pp. 305-306). Serían ambos paradigmas los que corresponderían con el modelo liberal (la exaltación de los derechos individuales) y el modelo republicano (la exaltación de la voluntad política popular).
Dicha caracterización resulta importante en cuanto la Democracia Deliberativa ha sido concebida, por autores como Habermas, como un modelo que propone la superación de ambos modelos, sin desechar sus principales elementos. De esta forma, si en el modelo liberal el Estado debe garantizar los derechos subjetivos; en el republicano, tiene por objetivo garantizar el cumplimiento de la voluntad "popular", Habermas - según refiere Héctor Domínguez - propone que la razón de ser del Estado debe consistir en:

la salvaguarda de un proceso inclusivo de formación de la opinión y la voluntad común, en la que los ciudadanos libres e iguales se entienden sobre las metas y normas que serían de interés común para todos, para entenderse respecto de los criterios a partir de los cuales se puede establecer qué es lo justo y lo injusto, es decir, establecidos los derechos, la función del Estado será garantizarlos y protegerlos para que los ciudadanos en el ejercicio de estos [derechos] no atropellen a otros. (Domínguez, 2013, p. 307)

Es por ello que María Guerra (2015) denomina a la democracia deliberativa en los términos de Habermas, como una "inclusión radical"; pues —según se desprende del párrafo anteriortodos los ciudadanos y grupos sociales se ven involucrados en la toma de decisiones públicas, en cuanto esta (la ciudadanía) ha decidido autodeterminarse, y por ello el Estado debe garantizar tanto las libertades negativas (ligadas a la libertad individual) y las libertades positivas (ligadas a derechos colectivos), las cuales serían complementarias e igual de importantes (pp. 111-112). Conciliando ambos modelos y evitando las exclusiones que surgen cuando se imponen los derechos individuales frente a la voluntad popular, o viceversa.

Tal como señalan Denilson Luis Werle y Rúrion Soares Melo (2007), este planteamiento pondría en cuestión a las teorías hegemónicas de la democracia del siglo XX - como el elitismo democrático o las teorías de la escuela racional-, las cuales coinciden en que a través 
de mecanismos de agregación de preferencias como el voto, las instituciones que organizan el poder político deben articular los intereses individuales con los intereses generales de la comunidad política (p. 7). Precisamente, el punto débil de dicho modelo agregativo (siendo el presupuesto básico de la democracia deliberativa) es el hecho de que existen profundos desacuerdos en la sociedad, los que pueden ser de preferencias e intereses (según plantean Barber, Habermas o Bohman) o de carácter moral (en la opinión de Rawls, Gutmann y Thompson) (Cortina, 2007, p. 146).

En tal sentido la crítica de la democracia deliberativa parte del alejamiento de concepciones puramente cuantitativas de esta, relacionadas solo con la porción de la población que tiene derecho a voto, antes bien "se relaciona con auto-determinación, con la posibilidad de que la gente ejerza un mayor control sobre las circunstancias políticas y económicas de sus vidas" (Guerra, 2015, p. 112). Respecto a las teorías de la democracia deliberativa, Werle y Melo afirman:

...los procesos de toma de decisiones tienen que estar fundados en la deliberación de los ciudadanos en fórums públicos amplios de debate y negociación. Por tanto, las prácticas e instituciones democráticas deben de tener como presupuesto la posibilidad de uso público de la razón, libre e inclusiva, según el cual las deliberaciones políticas sobre cuestiones fundamentales no resultan de un proceso mecánico de agregación de preferencias fijas y preexistentes al juego político, sino de un proceso de formación y transformación de las propias preferencias y de los intereses particulares, en el sentido de alcanzar acuerdos políticos que tengan a su favor una pretensión de racionalidad. (Luis-Werle \& SoaresMelo, 2007,pp. 7-8)

A partir de una lectura de la propuesta de democracia deliberativa de Habermas, María Guerra establece las siguientes características de este modelo:
- No hay a priori una distinción público/privado: todo puede ser objeto de deliberación pública si así es propuesto por la ciudadanía.

- Los temas de la agenda pública se definen y redefinen en la deliberación pública. La delimitación de lo justo es producto de los debates y controversias entre la ciudadanía.

- Tanto la libertad negativa como la libertad positiva son interdependientes y tienen un mismo origen en los procesos democráticos. Habermas intenta reconciliar las tradiciones liberales y republicanas.

- La identidad ciudadana es una identidad fluida que implica una actitud reflexiva y crítica de los individuos [...].

- La solidaridad, como principio político, significa atender e interpretar las necesidades de los otros. Todos deben disfrutar de un esquema similar de libertades, lo que supone una apuesta por la igualdad.

- La mayor relevancia la cobran los derechos políticos entendidos como derechos de participación y asociación, pero también de libertad de opinión, en el proceso deliberativo y en las instituciones democráticas.

- El poder reside en la acción de la ciudadanía por lo que el dinamismo de la sociedad civil es trascendental para activar los potenciales democráticos del Estado.

- La política es un fin en sí misma, considerada como el lugar de los procesos comunicativos que incluyen diversidad de discursos, negociaciones y deliberaciones. (Guerra, 2015, pp. 114-115)

Gutmann y Thompson conceptualizan a la democracia deliberativa como un proceso en el cual los deliberantes intercambian razones con el fin de alcanzar "justos términos de cooperación social", esgrimiendo razones que deben ser públicamente accesibles a todos los afectados por una medida política, la cual deberá ser vinculante para todos los ciudadanos durante un periodo determinado de tiempo, resaltando su provisionalidad moral y política 
(Olivares, 2017, p. 169). Esto se traduce en la posibilidad de reaperturar el diálogo en cualquier momento, cuando se produzcan las condiciones necesarias y bajo los procedimientos establecidos para dicho propósito.

Así también, Elster — citado por Martí (2006, p. 23) - afirma que la noción de democracia deliberativa incluye dos aspectos: Por un lado el aspecto democrático, el cual implica "una toma de decisiones colectiva con la participación de todos aquellos que resultarán afectados por la decisión, o de sus representantes". Por otro lado, el aspecto deliberativo, que resulta fundamental para caracterizar y diferenciar esa concepción de la democracia de otras, donde se destaca el hecho de "que esta decisión debe ser tomada mediante argumentos ofrecidos por y a los participantes, que están comprometidos con los valores de racionalidad e imparcialidad".

José Luis Martí sostiene que si bien la definición dada por Elster es adecuada como definición mínima, omite un elemento muy importante: la democracia deliberativa tiene un carácter ideal, es decir, constituye un "ideal regulativo" entendido como "un horizonte normativo hacia el que debemos tender en la medida de lo posible. [...] un estado de cosas que evaluamos como deseable o correcto [...] puede ser empíricamente alcanzable o no alcanzable, sin que ello afecte a la validez normativa del ideal" (Martí, 2006, p. 25). Esto significa que su fundamento no es necesariamente empírico, no depende de un determinado estado de cosas; no obstante, al pasar a un segundo momento evaluativo, este ideal regulativo se traduce en algunas condiciones empíricas.

Nicolás Emanuel Olivares — basado en sus lecturas de Martí, Gutmann, Thompson, Rawls, Nino, entre otros - plantea la descomposición del concepto de democracia deliberativa en tres elementos: ideal regulativo, sujeto y proceso.
El primero de estos elementos es entendido como la oposición al ideal democrático agregativo, expresado en la negociación y el voto, para lo cual propone la argumentación como método político; es decir, "las normas y medidas políticas son democráticamente legítimas si y solo si resultan de la deliberación pública entre ciudadanos y representantes, y están justificadas en aquellas razones públicas que resultan aceptables para los deliberantes" (Olivares, 2017, pp. 179-180).

Respecto al sujeto, la democracia deliberativa - sustentada en los principios de inclusión, igualdad e imparcialidad - postula que en el proceso deliberativo todos los ciudadanos "deben ser tratados como agentes morales y epistémicamente capacitados para intervenir en el debate público y tomar decisiones políticas; [...] deben escucharse, respetarse y discutirse los argumentos de todos los posibles afectados por la norma o medida política en cuestión" (Olivares, 2017, p.181).

Sobre el proceso, señala que el ideal regulativo se debe materializar a través de un ejercicio de discusión para la toma de decisiones políticas, adoptando un criterio "epistémico intersubjetivo de validación de resultados", contrastando con los modelos de democracia agregativa, comprendiendo a las preferencias como estáticas, y siendo sus resultados posibles de ser revisados en un proceso que cumpla con los criterios de "respeto mutuo entre ciudadanos, así como facilitar la resolución de aquellos desacuerdos políticos-morales existentes en una determinada sociedad" (Olivares, 2017, p. 181).

Al presentarse el modelo de la democracia deliberativa como un ideal regulativo que pretende superar las contradicciones y exclusiones de los modelos liberal y republicano de democracia, articulando los elementos de ambos, María José Guerra realiza un cuadro comparativo de los tres modelos (liberal, republicano y deliberativo) a partir de una lectura de Habermas: 
Tabla 1. Cuadro comparativo entre los modelos liberal, republicano y deliberativo

\begin{tabular}{|c|c|c|}
\hline LIBERALISMO & REPUBLICANISMO & $\begin{array}{l}\text { DEMOCRACIA } \\
\text { DELIBERATIVA }\end{array}$ \\
\hline $\begin{array}{l}\text { Distinción } \\
\text { público/privado: } \\
\text { se ponen límites a } \\
\text { los contenidos del } \\
\text { discurso público. }\end{array}$ & $\begin{array}{lr}\text { Distinción } & \\
\text { público/privado: } & \text { se } \\
\text { ponen límites a los } \\
\text { contenidos } & \text { del } \\
\text { discurso público. } & \end{array}$ & $\begin{array}{l}\text { No hay distinción } \\
\text { público/privado: } \\
\text { los temas de la } \\
\text { agenda pública se } \\
\text { definen en la } \\
\text { deliberación } \\
\text { pública. }\end{array}$ \\
\hline $\begin{array}{l}\text { Neutralidad del } \\
\text { Estado en asuntos } \\
\text { privados. }\end{array}$ & $\begin{array}{l}\text { Separación de lo } \\
\text { público y las } \\
\text { cuestiones económicas } \\
\text { y privadas. }\end{array}$ & $\begin{array}{l}\text { Definición de lo } \\
\text { justo y toma de } \\
\text { medidas políticas a } \\
\text { partir de la } \\
\text { deliberación } \\
\text { pública. }\end{array}$ \\
\hline $\begin{array}{l}\text { Predominio de lo } \\
\text { correcto (right) } \\
\text { sobre los criterios } \\
\text { de la buena vida. }\end{array}$ & $\begin{array}{l}\text { La ciudadanía } \\
\text { configura la identidad } \\
\text { de los individuos y los } \\
\text { integra en el bien } \\
\text { común. }\end{array}$ & $\begin{array}{l}\text { La identidad } \\
\text { ciudadana es una } \\
\text { identidad fluida } \\
\text { que implica una } \\
\text { actitud reflexiva y } \\
\text { crítica de los } \\
\text { individuos. }\end{array}$ \\
\hline $\begin{array}{lr}\text { Los } & \text { ciudadanos } \\
\text { son considerados } \\
\text { portadores } & \text { de } \\
\text { derechos. } & \text { La } \\
\text { solidaridad } & \text { no es } \\
\text { una } & \text { virtud } \\
\text { necesaria } & \text { para la } \\
\text { ciudadanía. } & \end{array}$ & $\begin{array}{lr}\text { La solidaridad } & \text { se } \\
\text { considera } & \text { una } \\
\text { interdependencia } & \\
\text { mutua } & \text { entre } \\
\text { ciudadanos. } & \end{array}$ & $\begin{array}{l}\text { La solidaridad } \\
\text { significa } \\
\text { interpretar } \\
\text { atender y } \\
\text { necesidades de los } \\
\text { otros. }\end{array}$ \\
\hline $\begin{array}{l}\text { Predominio de la } \\
\text { libertad negativa: } \\
\text { importancia de los } \\
\text { derechos } \\
\text { individuales frente } \\
\text { a los demás y al } \\
\text { Estado. No } \\
\text { interferencia. }\end{array}$ & $\begin{array}{lrr}\text { Predominio } & \text { de } & \text { la } \\
\text { libertad } & \text { positiva, } \\
\text { entendida como no } \\
\text { dominación } \\
\text { autogobierno. }\end{array}$ & $\begin{array}{l}\text { Tanto la libertad } \\
\text { negativa como la } \\
\text { libertad positiva } \\
\text { son } \\
\text { interdependientes y } \\
\text { co-originarias. }\end{array}$ \\
\hline $\begin{array}{lr}\text { Los } & \text { derechos } \\
\text { políticos } & \text { son } \\
\text { instrumentales } \\
\text { respecto a los } \\
\text { intereses privados } \\
\text { (visión agregativa } \\
\text { de la esfera } \\
\text { pública). }\end{array}$ & $\begin{array}{l}\text { Los derechos políticos } \\
\text { constituyen un fin en } \\
\text { sí mismos. } \\
\text { Identificación de los } \\
\text { intereses privados con } \\
\text { el interés público } \\
\text { (visión integradora de } \\
\text { la esfera pública). }\end{array}$ & $\begin{array}{l}\text { Relevancia de los } \\
\text { derechos políticos } \\
\text { como derechos de } \\
\text { participación } \\
\text { (visión } \\
\text { integradora) }\end{array}$ \\
\hline $\begin{array}{l}\text { El poder político } \\
\text { es algo ajeno a los } \\
\text { ciudadanos. }\end{array}$ & $\begin{array}{l}\text { El poder reside en la } \\
\text { acción de la } \\
\text { ciudadanía. }\end{array}$ & $\begin{array}{l}\text { El poder político es } \\
\text { poder } \\
\text { comunicativo y } \\
\text { reside en la acción } \\
\text { de la ciudadanía. } \\
\text { Importancia de la } \\
\text { sociedad civil. }\end{array}$ \\
\hline $\begin{array}{l}\text { La política es una } \\
\text { actividad } \\
\text { instrumental para } \\
\text { armonizar } \\
\text { intereses } \\
\text { particulares. }\end{array}$ & $\begin{array}{l}\text { La política es un fin en } \\
\text { sí misma y confiere } \\
\text { dignidad y a la } \\
\text { ciudadanía. }\end{array}$ & $\begin{array}{l}\text { La política es un } \\
\text { fin en sí misma y } \\
\text { arraiga en la } \\
\text { racionalidad } \\
\text { comunicativa. }\end{array}$ \\
\hline $\begin{array}{l}\text { No exige grandes } \\
\text { obligaciones } \\
\text { cívicas a la } \\
\text { ciudadanía. }\end{array}$ & $\begin{array}{l}\text { Requiere ciudadanos } \\
\text { que ejerciten la virtud } \\
\text { cívica en el transcurso } \\
\text { de sus acciones } \\
\text { públicas. }\end{array}$ & $\begin{array}{l}\text { Necesita } \\
\text { ciudadanos } \\
\text { preparados en la } \\
\text { deliberación, } \\
\text { capaces de } \\
\text { desentenderse de } \\
\text { sus intereses } \\
\text { privados. }\end{array}$ \\
\hline
\end{tabular}

\section{LEGITIMIDAD DEMOCRÁTICA Y DEMOCRACIA DELIBERATIVA}

Siguiendo a Fabienne Peter, citada por Alles (2013), podemos definir la legitimidad democrática como "un concepto normativo distintivo que hace referencia a las condiciones que deben aplicarse a la toma de decisiones democráticas $[\ldots]$ significa la autorización para utilizar el poder político" (p. 2). De esta manera, las múltiples concepciones de democracia traerán consigo una serie de condiciones específicas que otorgarán mayor o menor legitimidad a las instituciones políticasjurídicas; en este sentido, las teorías de la democracia deliberativa establecerán sus propias condiciones de legitimidad.

Tal como ya tratamos en el apartado anterior, la democracia deliberativa consiste en un ideal regulativo que nos conduce a establecer como condición de la legitimidad democrática a las normas, instituciones y medidas políticas. Según señala Nicolás Olivares (2017), se trata de "la existencia de un proceso intersubjetivo de justificación moral, en el cual los afectados por dicha decisión deliberen públicamente entre sí" (p. 169). El cumplimiento de estas condiciones produciría "un resultado justo y políticamente vínculante" (Alles, 2013, p. 2), el cual sería la finalidad primordial y el fundamento de la reflexión sobre las condiciones de la legitimidad democrática de la democracia deliberativa.

De esta manera, la idea central de la legitimidad democrática — desde la óptica de la democracia deliberativa como señala Joshua Cohen, citado por Martí (2006) - radica en que "la autorización para ejercer el poder del Estado debe emanar de las decisiones colectivas de los miembros de una sociedad que son gobernados por este poder" (p. 141). En este proceso, al ser gradual, según afirma Nicolás Alles (2013), “el grado de legitimidad de cada procedimiento dependerá de cuántas condiciones pueda satisfacer y cómo ha de satisfacerlas" (p. 2). Al respecto, María Guerra sostiene que la democracia deliberativa es un modelo que presenta una ventaja respecto al problema de la legitimidad de las instituciones: 
... las instituciones pueden reclamar para sí el ejercicio del poder, esto es del poder legítimo, porque sus decisiones representan de manera igualitaria el punto de vista y los intereses de todos. Esta condición solo puede satisfacerse si tales decisiones están abiertas a los procesos de deliberación pública entre ciudadanos libres e iguales. (Guerra, 2015,p. 113)

Cobran importancia, entonces, las condiciones en las cuales las personas pueden acceder al diálogo, así también la capacidad de justificación de las decisiones a partir de una práctica argumentativa donde la persuasión va acompañada de la aceptación de condiciones como la posibilidad de verse influido y cambiar de preferencias en dicho proceso.

Es por ello que la esencia de la democracia deliberativa puede ser entendida del modo como Dryzek - citado por Cortina - lo hace:

La legitimidad de la democracia estriba en la capacidad o la oportunidad que tienen los sujetos de las decisiones colectivas de participar en deliberaciones efectivas; las exigencias tienen que justificarse de modo que la gente, reflexionando sobre ellas, pueda aceptarlas. A lo cual se añade un elemento clave, y es la convicción de que las preferencias de los individuos o de los grupos pueden transformarse a lo largo del proceso de deliberación, en el que las gentes emplean la persuasión, más que la manipulación o la coerción. (Cortina, 2007 p. 146)

Para comprender este problema de la legitimidad democrática en la teoría de la democracia deliberativa, podemos basarnos en Habermas, quien la concibe como una propuesta de superación de la tensión producida en los modelos liberales y republicanos de la democracia; es decir, "entre la defensa de la primacía de los derechos humanos individuales (liberalismo) y los que ponen el acento en la idea de soberanía popular (Republicanismo igualitario)" (Pineda, 2002), incorporando los problemas fundamentales de ambas teorías y reformulándolas en lo que él denomina la teoría del discurso. Habermas explica este proceso de la siguiente manera:

...una interna conexión entre negociaciones, discursos de autocomprensión y de discursos referentes a la justicia, y cimenta la presunción de que bajo tales condiciones se alcanzan resultados racionales o equitativos. Con ello, la razón práctica se repliega desde la noción de los derechos universales del ser humano o desde la eticidad concreta de una comunidad determinada a aquellas reglas del discurso y formas de la argumentación que toman su contenido normativo de la base de validez de la acción orientada hacia el entendimiento, $y$, en definitiva, de la estructura de la comunicación lingüística. (Alles, 2013,p. 8)

Habermas —según refiere Nicolás Alles - cuestiona así ambas posturas ( $\sin$ descartar sus principales elementos) por considerarlas reduccionistas; ello a partir de la idea de intersubjetividad de orden superior, la cual se produce en un nuevo escenario denominado la esfera pública, en el contexto de una "sociedad descentrada, compuesta por subsistemas sociales relativamente autónomos" (Alles, 2013, p. 10). Dicha esfera pública, para María Guerra consiste en lo siguiente:

El lugar en el que se forma la llamada opinión pública y en la que se producen procesos de aprendizaje moral y políticos colectivos que pueden desencadenar cambios de valores sociales. Esta esfera pública debería estar en sintonía con tres condiciones normativas: reciprocidad igualitaria, auto-adscripción voluntaria y libertad de asociación así como de desafiliación. (Guerra, 2015, pp. 113-114) 
En el modelo de democracia deliberativa, la construcción de la esfera pública parte de la crítica a su concepción de "mercado", donde los sujetos buscan maximizar sus beneficios con un objetivo productivo (en términos económicos) y donde además las instituciones excluyen las demandas de las mayorías, por tanto, no permiten la optimización de tales beneficios (Cuchumbe \& Giraldo, 2013, p. 144). Esta concepción de la esfera pública como un espacio dialógico donde los participantes presentan determinadas condiciones, permite perseguir que el resultado de la práctica argumentativa sea justo y racional.

De esta manera, en su libro Facticidad y validez: Sobre el derecho y el Estado democrático de derecho en término de la teoría del discurso, Habermas señala que "validez son aquellas decisiones (y solo aquellas) en las que todos los que pudieran verse afectados concurren a prestar su asentimiento como participantes en discursos racionales" (Habermas, 2005, p. 172). Carlos Giuffré (2016), descompone este principio "habermasiano", al señalar que la validez de la cual habla Habermas designa lo legítimo, y debe ser producto de "un reconocimiento intersubjetivo de una pretensión de validez [...] y con afectado se llama a cualquiera a quien pueda concernir en sus intereses las consecuencias a que alcance dar lugar a una determinada práctica regulada por normas" ( $\mathrm{p}$. $3)$.

Para Habermas, las pretensiones de validez se ubican en el acto intersubjetivo de la comunicación como un "conjunto de expectativas que tenemos en relación con nosotros mismos y los otros" (Guerra, 2015, p. 59). De tal forma, según refiere María José Guerra, surgen cuatro pretensiones fundamentales de validez:

- Inteligibilidad: que lo que digo y expreso sea entendible por los otros.

- Verdad: que los hechos y datos que refiero sean fiables en la medida de lo posible.

- Validez moral: corrección o rectitud, esto es, una pretensión de honestidad y conducta cabal en las relaciones intersubjetivas.

- Sinceridad: lo que expreso se corresponde con mis estados interiores sin simulación o falsedad (Guerra, 2015, p. 89).

El rol del afectado resulta fundamental en el proceso de deliberación, y será uno de los principales elementos que otorgará legitimidad a determinadas prácticas; sin embargo, esta participación puede ser ejercida de diversas formas, siempre que se inserte en lo que Habermas denomina discurso racional.

Por discurso (Diskurs) Habermas se refiere al debate o controversia, y se explica en cuanto la ética habermasiana se basa en el diálogo éticopolítico-intersubjetivo, dejando atrás el "monólogo moral" de la filosofía moderna, y la conciencia individual como sujeto moral de la ética kantiana; lo cual abre paso en su propuesta de ética discursiva, partiendo del lenguaje como origen y articulador del individuo en la sociedad, a la idea de la "comunidad de diálogo" (Guerra, 2015, p. 81).

La propuesta de la ética del discurso que propone Habermas, como fundamento de la democracia deliberativa, tiene los siguientes rasgos básicos:

- El Procedimentalismo, de claro carácter democrático. La intención de Habermas es que se llegue a consensos a través del proceso argumentativo de fundamentación de normas.

- El Deontologismo que implica se deba determinar principios y normas morales que guíen nuestro comportamiento.

- El Cognitivismo señala que debemos optar por la validez moral indicada por el consenso racional, esto es, solo el acuerdo intersubjetivo de todos es la prueba de la validez de normas y principios.

- El Universalismo, por último, remite al grado de generalización de las normas que debe ser el máximo posible $(2015$, p. 84$)$.

Respecto al discurso racional, Habermas señala el conjunto de elementos que intervienen $-\mathrm{y}$ se relacionan-en dicho proceso: 
Y por "discurso racional" entiendo toda tentativa de entendimiento, acerca de pretensiones de validez que se hayan vuelto problemáticas en la medida en que esa tentativa tenga lugar bajo condiciones de comunicación que dentro de un ámbito público construido y estructurado por deber ilocucionarios posibiliten el libre procesamiento de temas y contribuciones, de informaciones y razones. Indirectamente esa expresión se refiere también a las "negociaciones" en la medida en que estas vengan reguladas también por procedimientos discursivamente fundados. (Habermas, 2005, pp. 172173)

Basándose en dichos supuestos, Habermas critica posiciones elitistas respecto al problema de la legitimidad como la de Weber, el cual sostiene que los regímenes políticos por sí solos despertarían la creencia en su legitimidad en determinado momento. Para Habermas, no basta la creencia por sí sola, si esta no se encuentra fundada en argumentos, lo cual implicaría que la ciudadanía tome una actitud activa para poder construir la legitimidad a partir de consensos derivados de "un activo diálogo y debate en el espacio público" (Vergara, 2005, pp. 81-82).

Esta evaluación de las prácticas y las instituciones políticas, desde el ideal regulativo de la democracia deliberativa, incorpora preocupaciones empíricas y normativas, según señala Greppi, en cuanto no son por un lado solo criterios procedimentales, ni exclusivamente el reflejo de los "principios de la razón pública", sino "han de ser entendidas al mismo tiempo como el marco de referencia indispensable en los procesos de formación de la opinión y de la voluntad" (Olivares, 2017, p. 183). Entonces, retomando la definición de la legitimidad democrática en términos de la democracia deliberativa, esta se entiende como el cumplimiento de determinadas condiciones, lo cual significa que se trata de un proceso gradual. No existe consenso respecto a dichas condiciones por los teóricos de la democracia deliberativa, sin embargo, algunas propuestas como la de Greppi establecen una serie de principios generales y específicos que sirven de criterios evaluativos. Olivares (2017, pp. 184180) señala los siguientes:

\section{Principios generales}

1) El principio normativo de inclusión hace referencia a la participación de los "afectados" - término utilizado también por Habermas - por el tema objeto de la deliberación; principio que debe ser posible de manera genuina y adecuada, o representativa en la etapa de deliberación y decisión política.

2) El principio normativo de paridad se relaciona con el trato de los afectados en cuanto seres racionales, razonables y de igual dignidad política "siendo respetados por igual sus argumentos, garantizando una equitativa participación en el debate, así como un igualitario poder de influencia y control sobre la decisión posteriormente adoptada".

3) El principio empírico de traslación, se refiere a que resulta indispensable "que los representantes políticos garanticen la formación libre y debidamente informada de las preferencias políticas ciudadanas, receptándolas en sus debates institucionales formales y transformándolas en normas jurídicas positivas".

4) El principio empírico de capacidad hace referencia a que "los representantes políticos de los ciudadanos, sea como sujetos individuales o como instituciones públicas, sean capaces de implementar la voluntad política construida deliberativamente en el circuito comunicativo antes mencionado".

\section{Principios específicos o criterios evaluativos específicos}

1) El primero señala que la condición de sujeto deliberativo debe recaer en los ciudadanos y no solo en sus 
representantes, como anota Nicolás Olivares: "lo deseable es alcanzar el mayor grado posible de participación política efectiva de los ciudadanos, sin por ello suprimir las necesarias instancias deliberativas de sus representantes".

2) El segundo principio o criterio específico consiste en adoptar una "concepción contextualista epistémica de los diseños institucionales", la cual contiene los siguientes criterios de evaluación para determinar el grado de legitimidad política de un diseño institucional: i) los principios políticos normativos contenidos en el ideal democrático deliberativo; y ii) las particulares condiciones normativas y empíricas no ideales propias del sistema jurídico y sociedad democrática en la cual se inserta dicho diseño.

3) El tercero se refiere a la relación entre el poder constituyente y los poderes constituidos, lo que se denomina "concepción deliberativa epistémica". Esta implica, siguiendo algunas ideas de Roberto Gargarella, "una relación dialógica cooperativa entre ellos, por oposición a las concepciones de estricta separación de poderes, que propone una relación neutral, y la de frenos y contrapesos, la cual postula una lógica agónica de interacción entre poderes”.

4) El cuarto principio específico implica adoptar como criterio normativo una "concepción sistémica" de la democracia deliberativa, la que comprende a su vez las siguientes reglas para evaluar el diseño institucional (refiriéndose por e j e m p lo, a 1 c o n t rol d e constitucionalidad): analizar la legitimidad de las decisiones políticas que se toman en las instituciones, a partir de su contribución a la calidad del sistema deliberativo, contrario a una evaluación aislada de la calidad epistémica y procedimental de tales decisiones; así como tomar en cuenta que dicho sistema comprende la interactuación de los foros políticos deliberativos y no deliberativos.

Por otra parte, José Luis Martí, en su obra La República Deliberativa (2006, pp. 90-95), propone ocho principios estructurales del proceso democrático deliberativo; los cuales, en nuestra opinión, resultan útiles para poder determinar el grado de adecuación al ideal regulativo de la democracia deliberativa.

1) Principio de la argumentación, entendiendo que la democracia deliberativa en cuanto proceso discursivo se diferencia de otros modelos basados, por ejemplo, en el voto como método de agregación de preferencias; pues existe comunicación con el objetivo de transformar las preferencias de los demás; sin embargo, a diferencia de otras formas de comunicación, como la negociación o la persuasión retórica, dicha transformación pretende ser razonada.

2) Principio de procedimiento colectivo, se trata de un proceso de reflexión dialógica en que las diversas propuestas, los diversos argumentos y las diversas evaluaciones de cada argumento se cruzan intersubjetivamente.

3) Principio de inclusión, hace referencia a que "todos los potencialmente afectados por una decisión deben tener la capacidad de participar en el proceso deliberativo que se encamina a tomar dicha decisión".

4) Principio de publicidad, posee una doble dimensión del procedimiento comunicativo: por un lado "se basa en la sinceridad y transparencia de razones y opiniones, y por otra parte cuando la deliberación se produce entre representantes políticos, [...] funciona como una de las garantías democráticas vinculadas al ejercicio de una correcta representación".

5) Principio de procedimiento abierto (opennes), el cual comprende la 
flexibilidad respecto a la forma y el contenido de las decisiones. Por otro lado, la apertura tiene que ver con su naturaleza autorreferente, en la medida que sirve para reflexionar respecto a las condiciones y demás cuestiones del mismo proceso.

6) Principio de procedimiento continuo (ongoing), se refiere a que en el proceso "nunca se dejan de examinar nuevas razones en favor o en contra de las alternativas de decisión, o al menos nunca se cierra la puerta a esa posibilidad. Y eso significa que los resultados del proceso son siempre provisionales".

7) Principio de libertad de los participantes, como fundamento de la democracia deliberativa, se refiere al valor que se le da a la autonomía tanto pública como privada, lo que se traduce en tres libertades formales dentro del procedimiento deliberativo: el libre acceso, la libre participación y la libre participación en la decisión.

8) Principio de igualdad formal de los participantes, entendida como una igualdad de tipo procedimental y no material, pues esta corresponde a las precondiciones de la democracia deliberativa. Esto significa que los participantes deben tener la misma capacidad de influencia política, esto es, igual oportunidad de determinar la decisión final.

\section{AMODO DE CONCLUSIÓN}

Desde la perspectiva de la democracia deliberativa, se ha señalado algunos aspectos importantes, a modo de punto de partida, en la evaluación de las condiciones que deben cumplir las instituciones y sus prácticas a fin de ser legítimamente democráticas. Asimismo, es importante recordar que para que exista un proceso adecuado en los términos de la democracia deliberativa, deben crearse los mecanismos que permitan la participación de quienes consideren que serán afectados por determinada medida; por lo cual, se tiene que llevar la opinión pública a los espacios donde se toman las decisiones, en condiciones de igualdad, en un procedimiento abierto a la construcción colectiva de significados sin olvidar, además, que este modelo se traduce en decisiones de tipo provisional, pues el proceso deliberativo está inmerso en un diálogo continuo capaz de producir resultados racionales y justos.

\section{REFERENCIAS BIBLIOGRÁFICAS}

ALLES, Nicolás (2013), "El problema de la legitimidad en la democracia deliberativa”, VII Jornadas de Jóvenes Investigadores. Instituto de Investigaciones Gino Germani, Facultad de Ciencias Sociales, Buenos Aires: Universidad de Buenos Aires.

CORTINA, A. (2007), "Democracia deliberativa", en: RUBIO C. J.; A. SALMERÓN \& M. TOSCANO. (eds.), Ética, ciudadania y democracia, Contrastes: Colección Monográfica $N^{\circ} 12$, Málaga, 2007, pp. 143-161.

CUCHUMBE, N. \& J. GIRALDO (2013), "Aproximación a la democracia deliberativa de Habermas", Discusiones Filosóficas. Año $14 \mathrm{~N}^{\mathrm{o}}$ 22, enero-junio, pp. $141-159$.

DOMÍNGUEZ, H. (2013). "Democracia Deliberativa en Jurgen Habermas", Analecta política, Vol. 4, No. 5, 2013. pp. 301-323.

FISHKIN, J. (2009), When the People Speak: Deliberative Democracy \& Public Consultation, New York: Oxford University Press.

GUERRA, M. (2015). Habermas: La apuesta por la democracia, España: Batiscafo S.L.

HABERMAS, J. (2005), Facticidad y validez: Sobre el derecho y el Estado democrático de derecho en término de la teoría del discurso, Madrid: Editorial Trotta.

LUIS WERLE, D. \& R. SOARES MELO (2007), Democracia Deliberativa, Sao Paulo: Editora Singular - Esfera Pública. 
MARTÍ, J. L. (2006), La República Deliberativa, Madrid: Marcial Pons.

OLIVARES, N. (2017), "Democracia deliberativa y control de constitucionalidad: En defensa de un diseño multisituado", Revista de Derecho (Barranquilla) $\mathrm{N}^{\circ}$ 47, pp. 167-206.

PARKINSON, J. (2006), Deliberating in the Real World: Problems of Legitimacy in Deliberative Democracy, New York: Oxford University Press.

PINEDA GARFIAS, R. (2002). "La Democracia Deliberativa". Ius et Praxis [online]. vol.8, $n .2$, Talca.

VERGARA, J. (2005), "La concepción de la democracia deliberativa de Habermas", Quórum Académico, Vol. 2, $\mathrm{N}^{\mathrm{o}} 2$, julio-diciembre, pp. $72-88$. 